\title{
BEAD; A DIFFICULT TRACHEOBRONCHIAL FOREIGN BODY TO RETRIEVE; BRONCHOSCOPIST PERSPECTIVE.
}

\author{
ADNAN, M. RIAZ AFRIDI, M.SAEED, METHEW K JOSEPH, M. JAVAID, ISTERAJ \\ SHAHABI. \\ 1. Department of ENT, Hayatabad Medical Complex Peshawar \\ 2. New Medical Centre, Dubai
}

ABSTRACT
To know the efficacy of different instruments in retrieval of bead from tracheobronchial tree.

BACKGROUND: Bead is uncommon object in western world and therefore rarely recorded as a foreign body in tracheobronchial tree. No specific instrument being named for its retrieval. Our study focuses on different instruments we used and its outcome.

MATERIAL AND METHODS: This was retrospective study of foreign body bead impaction in tracheobronchial tree. All patients subjected to bronchoscopy with definite clinical findings of bead impaction on radiology or bronchoscopic examination were recorded, with different instruments used. In all cases Karlstorz rigid bronchoscopes of size 3.0 to 5.0 with fiber optic light used. Long bronchoscopic screw forceps, malleable forceps. Large nasal killian forceps was used after tracheostomy in some cases. Study period: 1st January 2008 to December 2012.

Site: ENT A unit Hayatabad Medical Complex Peshawar.

RESULTS: In our study of 3 years 32 cases were recorded with bead impaction in tracheobroncheal tree. $21(65.62 \%)$ were male and $11(34.37 \%)$ female. Age ranges below 1 year was $1(3 \%)$ case, between 1year and 2 years $6(18.75 \%)$ cases, 2 years to 3 years $21(65.62 \%)$ and 3 years and above 4 $(12.5 \%)$ cases recorded. $21(65.62 \%)$ beads were retrieved with malleable forceps, $8(25 \%)$ with long screw forceps, $1(3 \%)$ after tracheostomy with long killan nasal forceps and $2(6.25 \%)$ impacted beads were referred to cardiothoracic department for thoracotomy. $3(9.37 \%)$ beads were impacted in main trachea, $19(59.53 \%)$ in right main bronchus and $10(31.25 \%)$ in left main bronchus.

CONCLUSION: Bead is one of the difficult foreign body tracheobroncheal tree and needs special instruments for its removal.

KEY WORDS: Beeds, Boronchoscopy,

\section{INTRODUCTION:}

Foreign body aspiration is a very frequently occurring situation in pediatric practice; however. Foreign body aspiration can result in a great variety of symptoms of varying severity, or it even can be completely asymptomatic. These differences stem in part from a variety of diverse cultural, social and economic factors that include the parents' attitudes, eating habits, the availability and types of potentially threatening objects, and prevention strategies. ${ }^{1}$

Sometimes, Foreign body aspiration can be life threatening, acting as a significant cause of fatal home accidents in children younger than 6 years ${ }^{2}$ and even in developed countries like United states has a mortality ranges more than 300 deaths per year. This higher occurrence in children has also been confirmed in a retrospective Brazilian study. ${ }^{3}$

Foreign body aspiration occurs commonly in children between 1 and 3 years of age and consists most frequently of peanuts, seeds and other food particles and less frequently of plastic and metal particles.

Usually, there is a suggestive history of choking, although the classic clinical presentation with coughing, wheezing, and diminished air inflow is seen in less than $40 \%$ of the patients. ${ }^{4}$

Diagnosis of foreign body aspiration begins with patient history and clinical exploration and can be strengthened by radiographic findings. The most common indicators are air trapping, signs of infection, atelectasis, or radio opaque foreign bodies. $^{5}$ Hence, its important to note that 
children with these characteristic symptoms should undergo prompt bronchoscopy, regardless of radiographic findings ${ }^{6}$ Nowadays, bronchoscopy is essential if foreign body aspiration is suspected, first to confirm the diagnosis and also because it can be used for therapeutic treatment in the same stage. Before the advent of bronchoscopic techniques, the mortality rate for foreign body aspiration was around $50 \%$ of the cases. ${ }^{7}$ Now, with bronchoscopy available and advances in anesthesiology and surgical procedures, both mortality and morbidity have markedly diminished. 8,9 Foreign body aspiration and its evolution can lead to complications such as pneumomediastinum, pneumothorax, bronchial stenosis, abscess, atelectasis, foreign body dislodgment, and bronchospasm. 4, 6, 10

\section{MATERIAL AND METHODS:}

This was a retrospective study from 1st January 2008 to December 2012 in ENT and Head and Neck Surgery Department, Postgraduate Medical Institute, Hayatabad Medical Complex, Peshawar. In our study long thin malleable forceps, which was passed in the hole and the prongs opened up distal to the other end used along with long screw forceps which was inserted in the hole to fix inside and retrieved the foreign body. Record of foreign body bead impaction in tracheobroncheal tree, and its retrieval by different instruments were studied. All the cases of foreign bodies tracheobroncheal tree studied and patients with beed in tracheobroncheal tree selected. All the cases studied for impact beed retrieval by different instruments. All patients subjected to bronchoscopy with definite clinical findings of beed impaction on radiology or bronchoscopic examinations were recorded, with different instruments used. In all cases Karlstorz rigid bronchoscopes of size 3.0 to 5.0 with fiber optic light used. Long bronchoscopic screw forceps, malleable forceps and nasal killian forceps later after tracheostomy used.

Study period: 1st January 2008 to December 2012.
Site: ENT A unit Hayatabad Medical Complex Peshawar.

\section{RESULTS:}

In our study of 3 years 32 cases were recorded with bead impaction in tracheobroncheal tree. 21(65.62\%) were male and 11 (34.37\%) female. Age ranges below 1 year was $1(3 \%)$ case, between 1 year and 2 years $6(18.75 \%)$ cases, 2 years to 3 years $21(65.62 \%)$ and 3 years and above $4(12.5 \%)$ cases recorded. 21(65.62\%) beads were retrieved with malleable forceps, 8 $(25 \%)$ with long screw forceps, $1(3 \%)$ after tracheostomy with long killian nasal forceps and $2(6.25 \%)$ impacted beads were referred to cardiothoracic department for thoracotomy. 3 $(9.37 \%)$ beeds were impacted in main trachea, 19 $(59.53 \%)$ in right main bronchus and 10 $(31.25 \%)$ in left main bronchus.

\section{DISCUSSION:}

Aspirated foreign bodies continue to present challenges to otorhinolaryngologists. The major issue involves the accurate diagnosis, speedy and safe retrieval of the foreign body. The accurate diagnosis may elude even the experienced physician because often the initial choking incidents are not witnessed and the delayed symptoms may mimic other common conditions such as asthma, pneumonia, or upper respiratory tract infections. ${ }^{11}$ Presentation of foreign body tracheobroncheal tree varies depending on a number of factors. Age of the patient, type, size, site of foreign body and interval between inhalation and removal. ${ }^{12}$

In our case series of tracheobroncheal foreign bodies confirms the findings of studies by Cantaneo AJ and Wiseman NE. et al that majority of the children presenting with foreign body aspiration were under the age of 3 years. ${ }^{13}$, ${ }^{14}$ In our study $65 \%$ of children were below the age of 3 years. The natural urge to explore the objects by mouth, lack of molar teeth to crush nuts, crying and playing while eating and lack of parental supervision contributes to this hazard in this age group. While some literature age ranges 
from 1 year to 15 as some of foreign bodies are more common in adult age group. ${ }^{15}$

The male to female ratio in our study was almost 2:1 which is in concurrence with data recorded by Aravind Sehgal and Wiseman in his study., 8 Beed is netted in thin thread to make" tasbih" used for prayers and also as jewellery by girls in villages. Children usually break up this thread and play with beeds. As children have habit to put everything in mouth and play with it, chew, laugh and talk, make them vulnerable to inhale these objects. Beed by its shape and slippery nature is a difficult foreign body to retrieve. Beed is not used in western world, so in international literature, its difficult to find it as tracheobronchial tree foreign body. For this reason in Western world, no attempts have been initiated to make instrument for bead. Grasping by forceps is really difficult as it is usually fixed to tracheobronchial tree according to its size. As the bead in its middle have hole for thread to pass make the only access to bronchoscopist to pass his preferred instrument for retrieval. Dropping the foreign body during retrieval is a potentially life-threatening complication. ${ }^{16}$ The vocal cords should be well relaxed either by residual topicalization, paralysis, or an adequate depth of anesthesia, before removal of the foreign body. Dropping the foreign body has a higher correlation with the experience level of the bronchoscopist. ${ }^{17}$ The foreign body like bead has higher chance to fall down at vocal cord level, it is highly recommended to push the beed in a bronchus otherwise there is potential risk of complete air way obstruction. ${ }^{18}$

On two occasions bronchoscopist used option of tracheostomy and retrieved bead using long killian nasal forceps through tracheostomy. 2 cases in this study were sent to cardiothoracic unit for impacted beads for removal by thoracotomy procedure. Similar to our study Naseer.et al used effectively same thin malleable instrument in $83 \%$ of cases, while contrary to our findings the age group of maximal bead foreign bodies were around 6 to 8 years. ${ }^{19}$
Foreign body impaction in tracheobronchial tree occurs commonly in the right main bronchus than the left and less frequently in the larynx and trachea, ${ }^{14}$ this is because of anatomical position of right main bronchus, as it is more vertical and has larger diameter leading to more air entry than the left bronchus. In our study the common site for foreign body lodgment was right main bronchus followed by left main bronchus which is also found in study done by Tariq as well. ${ }^{20}$ The location of lodging of the foreign bodies in the right main bronchus $59 \%, 31 \%$ in left main bronchus and $9 \%$ in trachea.

\section{CONCLUSION}

Foreign body aspiration by children is a serious and life-threatening situation that requires special attention of parents and health-care providers. The symptoms are nonspecific, and the chest radiograph findings are frequently normal or display abnormalities uncharacteristic for foreign body aspiration. Instruments specifically for removal of bead should be designed to avoid morbidity and more serious complications. Attention must be given to early recognition of foreign body aspiration, as well as to prompt identification of complications caused by the bronchoscopy.

Table 1: Sex distribution.

\begin{tabular}{|l|l|l|}
\hline Sex & No & $\%$ \\
\hline Male & 21 & $65 \%$ \\
\hline Female & 11 & $35 \%$ \\
\hline
\end{tabular}

Table 2: Age distribution.

\begin{tabular}{|l|l|l|}
\hline \hline $1 \mathrm{~m}$ to 1year & 1 & $3.15 \%$ \\
\hline $1 \mathrm{yr}$ to 2years & 6 & $18.75 \%$ \\
\hline 2 years to 3years & 21 & $65.62 \%$ \\
\hline 3years and above & 4 & $12.5 \%$ \\
\hline
\end{tabular}

Table 3 Instruments.

\begin{tabular}{|l|l|l|}
\hline Instruments & No of cases & Percentage \\
\hline Long screw forceps & 8 & $25 \%$ \\
\hline Malleable forceps & 21 & $65 \%$ \\
\hline Long nasal killian & 2 & $6.25 \%$ \\
\hline
\end{tabular}


Table 4: Site of impaction of bead

\begin{tabular}{|l|l|l|}
\hline Site & No & Percentage \\
\hline Trachea & 3 & $9.375 \%$ \\
\hline Right main bronchus & 19 & $59.37 \%$ \\
\hline Left main bronchus & 10 & $31.25 \%$ \\
\hline
\end{tabular}

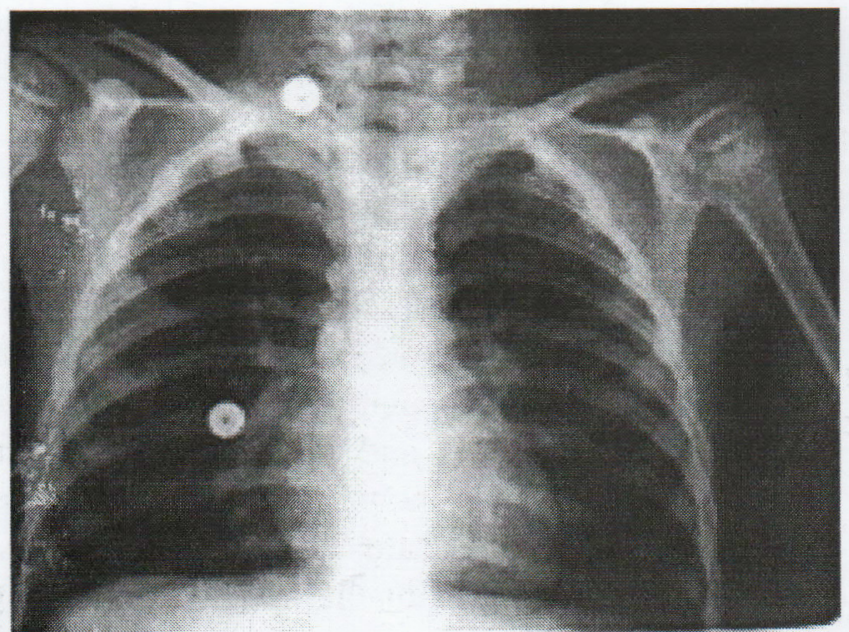

Plain $\mathrm{x}$-ray film: bead in right main bronchus

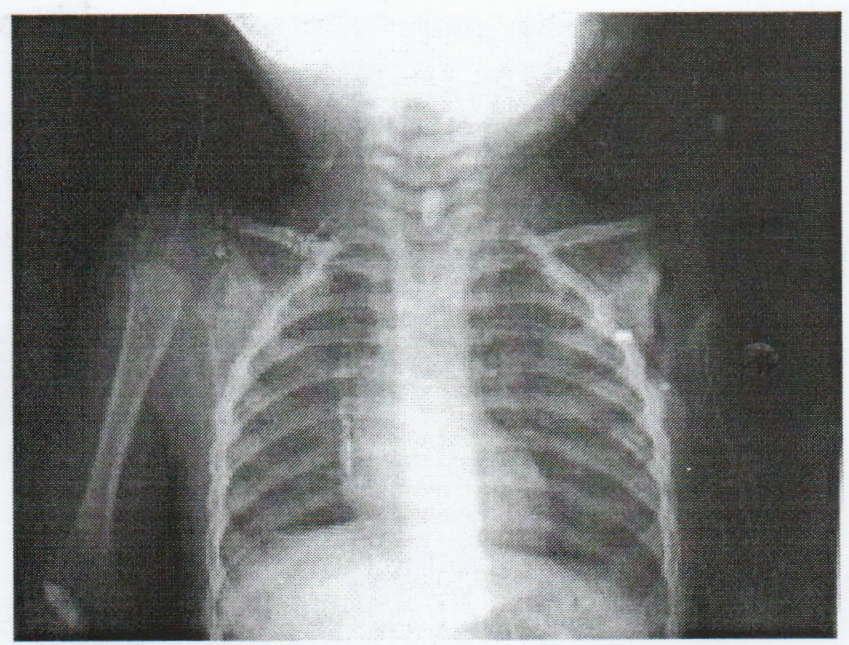

Plain x-ray film: bead in trachea

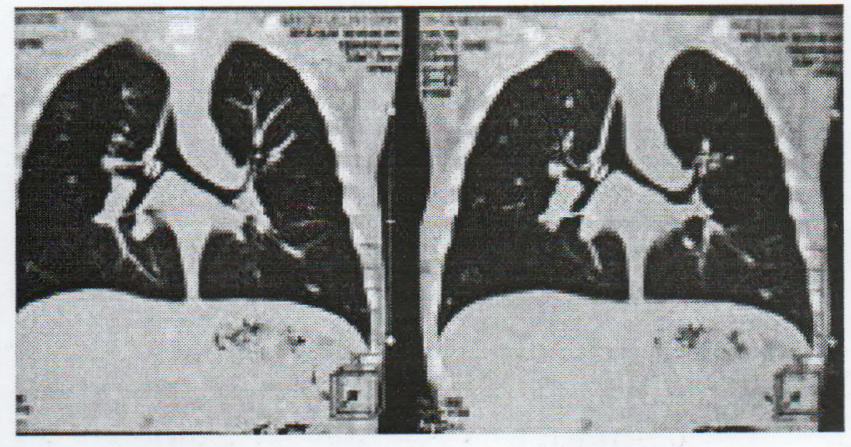

CT Scan Chest: bead in right main bronchus

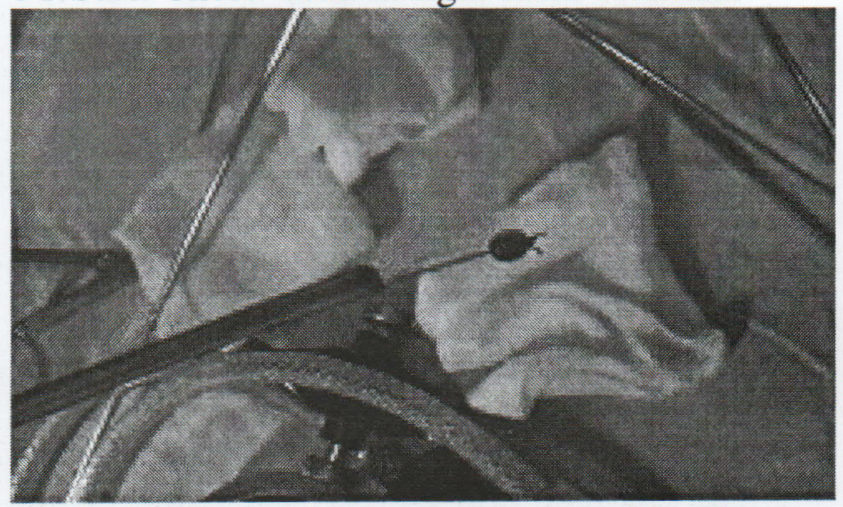

Bead grasped by passing malleable forceps through the hole and then held open

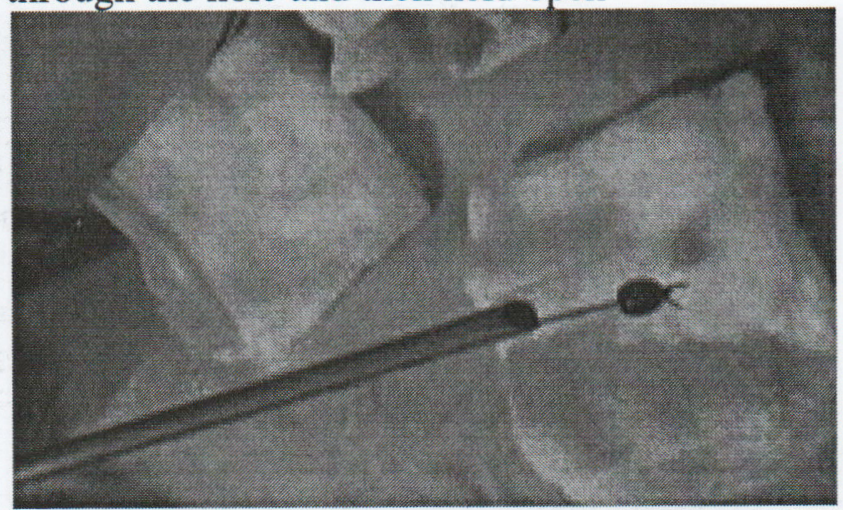

Bead grasped by passing malleable forceps through the hole and then held open

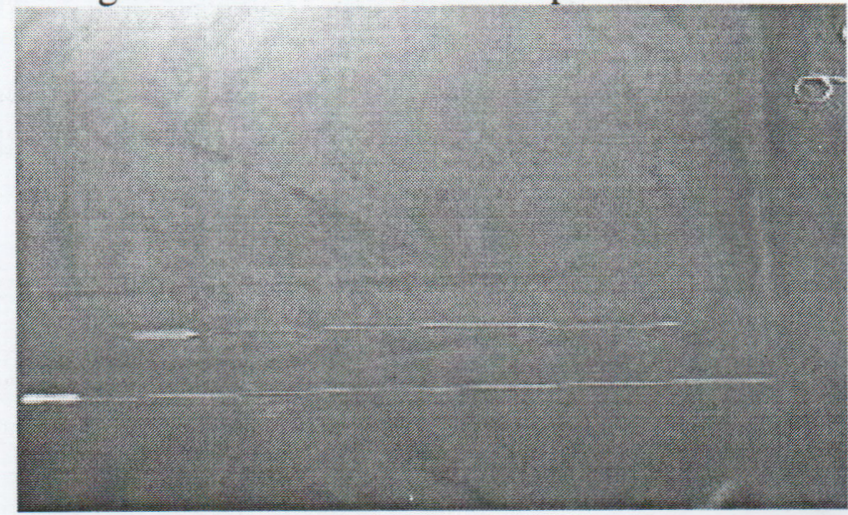

Long screw forceps.

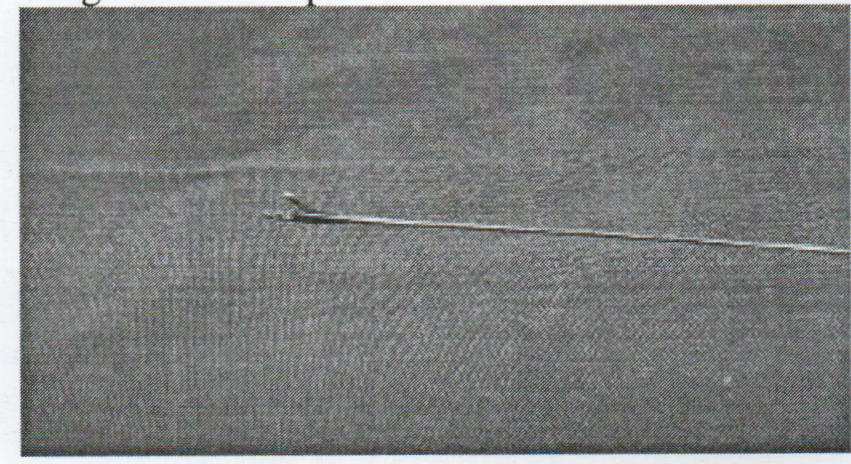

Malleable forceps held open 


\section{REFERENCES}

1. Samad L, Ali M, Ramzi H. Tracheobronchial foreign body aspiration in children: reaching a diagnosis. $\mathbf{J}$ Pak Med Assoc 1998; 48(11): 332-34.

2. CarluccioF, Romeo R. Inhaling foreign bodies: An epidemiological, clinical study of 92 cases. ActaOtorhinolaryngolItal 1997; 17(1): 45-51.

3. Ashoore A, Baraka M, Kholania E. Foreign bodies in paediatrictracheobrochialtree.Saudi Med J 1987; 5: 481-86.

4. Siddiqui MA, Banjar AH, Al-Najjar SM. Frequency of tracheobronchial foreign body in children and adolescents. Saudi Med J 2000; 21: 368-71.

5. AravindSehgal, Varinder Singh, Jagadish Chandra N. N. Mathur. Foreign body aspiration Indian paediatrics.2002; 39: 1006-10.

6. Hughes CA, Baroody FM, Marsh BR. Paediatric tracheobronchial foregn bodies: Historical review from the John Hopkins Hospital. Ann OtolRhinolLaryngol 1996; 105: 555-61.

7. Black RE, Johnson DG, Matlak ME. Bronhoscopic removal of aspirated foreign bodies in children.J PediatrSurg 1994; 29: 682-84.

8. Wiseman NE. The diagnosis of foreign body aspiration in childhood.J Pediatr.Surg 1984; 19: 53135.

9. Mutogama EK, Davis PJ. Anaesthesia for Ear, Nose and Throat Surgery. In: Smith's Anaesthesia for Infants and Children, 6th edition 1996; 669-74.

10. D. Agarwal et al. Management of foreign bodies in tracheobronchial tree in paediatric age group - A brief review. Indian J. Anaesth. 2001; 45(5): 348-49.

11. Ellen $M$ Friedman. Tracheobronchial foreign bodies.OtolarygolClin Nor Am 2000; 3 (1): 179-85.

12. Baharloo F, Veckemans F, Francis C, Beittlot MP, Roddenstein Do. Tracheobronchial foreign bodies: Presentation and Management in children and adults. Chest. May1999; 115 (5):1357-62.

13. CATANEO AJ, REIBSCHEID SM, RUIZ JUNIOR $\mathrm{RL}$ et al. - Foreign body in the tracheobronchial tree.ClinPediatr (Phila) 1997;36:701-6. [Links]

14. WISEMAN NE - The diagnosis of foreign body aspiration in childhood. J PediatrSurg 1984; 19:531535.

15. Ahmed Youssef ShaabanGadMohamed S. Hadidi. Removal of tracheobronchial foreign bodies using flexible and rigid bronchoscopy. Egyptian Journal of Chest Diseases and TuberculosisOctober 2012, Vol.61 (4):501-504.

16. Kumar S, Saxena AK, Kumar M, Rautela RS, Gupta $\mathrm{N}$, Goyal A. Anesthetic management during bronchoscopic removal of a unique, friable foreign body. AnesthAnalg2006; 103:1596-7.

17. Pawar DK. Dislodgement of bronchial foreign body during retrieval in children.PaediatrAnaesth2000; 10:333-5
18. Brown KL, Shefler A, Cohen G, DeMunter C, Pigott N, GoldmanAP.Near-fatal grape aspiration with complicating acute lung injury successfully treated with extracorporeal membrane oxygenation.PediatrCritCareMed2003;4:243-5

19. Naseer Ahmad, IhsanUllah, Muhammad Javaid, Muhammad HabibKhattak. Bead in Tracheobroncheal tree: A therapeutic challenge. JPMI.2006; 20:

20. Tariq. P. (Feb. 1999): Foreign body aspiration in children - a persistent problem. J. Pak. Med., Assoc. 49(2): 33-36

\section{CORRESPONDENCE ADDRESS:}

\section{Dr. Adnan}

Department of ENT

Hayatabad Medical Complex, Peshawar 